\title{
Ramón de la Cruz, Los Cazadores: preliminares para una edición
}

\author{
Iole Scamuzzi
}

Università degli Studi di Torino

iole.scamuzzi@unito.it

\section{Resumen}

En este artículo se analiza el texto literario de la zarzuela atribuida a Ramón de la Cruz Los Cazadores (1764), adaptación del drama con música de Carlo Goldoni Gli Uccellatori (1759). Tras una collatio entre los tres ejemplares conservados de la obra, se identifica el ejemplar más cercano a lo que debió salir de la pluma del autor, a través de la aplicación del concepto de diasistema elaborado por Cesare Segre en los años '80. Luego se confronta ese texto con la versión al castellano publicada en Barcelona en 1760 y con la princeps del libreto de Goldoni, para demostrar que el autor de la zarzuela traducía directamente del original, sin mediaciones, argumento que se utiliza al final para apoyar la tesis de la autoría de Don Ramón de la Cruz, buen conocedor del idioma italiano.

Palabras clave: Ramón de la Cruz; diasistema; Goldoni; zarzuela; traducción libretos de ópera.

\section{Abstract}

This essay studies the zarzuela Los Cazadores (1764), an adaptation of the opera buffa by Carlo Goldoni Gli Uccellatori (1759), which is said to have been made by Don Ramón de la Cruz. After a collation between the three existing witnesses of the zarzuela, the scholar uses Cesare Segre's concept of dia-system to establish which of them stands closer to the intentions of the author. This established text is subsequently compared to the translation of the opera into Spanish made in Barcelona in 1760, allowing to demonstrate that the adaptation is based on the original, and not on the translation. This argument is used to sustain that indeed Ramón de la Cruz must be the author of the zarzuela, since his competence in the Italian language was deep enough to allow him to do the job.

Keywords: Ramón de la Cruz; Diasystem; Goldoni; Zarzuela; translation of opera librettoes.

* El presente artículo se enmarca dentro de los proyectos de investigación FFI 2009-07293: Goldoni en España y FFI 2011-13321: Los drammi giocosi de Goldoni en la Península Ibèrica financiados por el Ministerio de Ciencia e Innovación. 
El 20 de Enero de 1764 se casaban la Infanta María Luisa de Borbón y el Archiduque Leopoldo, con gran festejo de toda la corte y, como era costumbre en estas circunstancias, especiales fiestas se celebraron en las residencias madrileñas de los embajadores de los países más amigos del régimen borbónico español. La boda de María Luisa y Leopoldo la celebraron los Embajadores de Francia, Austria, y Reino de las dos Sicilias en los primeros meses de 1764, pero hacía tiempo que la máquina de la corte organizaba dichos eventos. Las Fiestas abarcaron manifestaciones de tipo variado, como la gran marcha organizada por el conde de Rosemberg ${ }^{1}$, pero se centraron principalmente en el teatro con música, como confirma un documento conservado en la BNE: Decreto sobre los cómicos en fiestas de los embajadores, 29 Octubre, año de 1763²:

Ill.mo S.or,

Los embajadores de Viena, París y Nápoles deben hacer fiestas de teatro en sus casas en celebridad del casamiento de la S.ra Infanta D.a María Luisa con el Archiduque Leopoldo, y servirse para ellas de los comediantes de Madrid. Parece que las que llaman Autoras y todas las demás actrices han convenido de muy buena voluntad en presentarse y tomar las piezas y papeles que les han señalado los embajadores por medio de sus comisionados, y que sólo una actriz llamada La Guzmana se ha resistido con muy mal modo. Prevengo a V.S.I. de orden del Rey que la haga advertir que ya no sólo ha de aceptar el papel que ha revisado, sino que le ha de solicitar, y contentarse de que la den este, cualquier otro, o ninguno: intimándola de lo contrario el castigo competente; de modo que ella no quede consentida, y que otro ninguno no imite su atrevimiento, y que al mismo tiempo disponga V.S.I. que entiendan todos los comediantes que así será agradable, y que se esmeren en dar gusto a los citados embajadores, dedicándose a admitir dócilmente lo que de su parte se les quiera hacer aprehender para el mayor acierto y lucimiento de sus fiestas, como castigado él que falte, o dé motivo a sospechar que falta a ello, con cualquiera pretexto que sea. Dios cuide a V.S.I. m. a. s. Lorenzo 29 Octubre de 1763, El Marqués de Grimaldi S. Gobernador del Consesso.

Si en Octubre de 1763 ya se estaba conminando a la desobediente Guzmana ${ }^{3}$ a que aceptase el papel y el sueldo que le imponía la organización de las Fiestas, quiere decir que por aquel entonces estaban ya listas las obras que se pensaba representar, y entre ellas la zarzuela de Los Cazadores, que es una traducción de Gli Uccellatori de Goldoni, hecha probablemente por Ramón

1. David GonzÁlez Cruz, Las bodas de la realeza y sus celebraciones festivas en España y América durante el siglo XVIII, en "Espacio, tiempo y forma», serie IV, Historia Moderna, t. 10, 1997, pp. 227-261.

2. MSS/11265/42 BNE.

3. María de Guzmán, excelente cantante de Sainetes, famosa por su gallarda representación en el papel de Graciosa. Murió muy anciana a principios del xix tras muchos años de encierro, por haber perdido el juicio en 1778. (V. E. Cotarelo y Mori, Don Ramón de la Cruz y sus obras, Madrid, RAE, 1899, p. 525). Ella, al final, no formó parte del reparto de la zarzuela que estudiamos aquí; pero no puedo excluir que obtuviera un papel en alguna de las otras muchas que se representaron en estas fiestas. 
de la Cruz, y que se iba a estrenar en casa del embajador de Nápoles en el mes de Enero.

No se acaba de demostrar la atribución a Ramón de la Cruz de esta zarzuela, ya que ninguno de los ejemplares que de ella se han conservado lleva el nombre del sainetero, y no se encuentra en la lista de Sempere y Guarinos ${ }^{4}$. Explica así la situación Albert Recasens ${ }^{5}$ :

La Zarzuela Los Cazadores, o En la selva sabe amor tender sus redes mejor (1764), ejemplifica la temática de las atribuciones, a pesar de que se han conservado el texto adaptado y la música [...] La traducción se ha atribuido a Ramón de la Cruz desde inicios del siglo XIX, pero no se ha podido demostrar fehacientemente.

Cotarelo y Mori no pone en duda la paternidad del libreto y la Biblioteca Histórica Municipal de Madrid, que conserva los dos testimonios manuscritos que quedan del texto, los cataloga como obra del sainetero ${ }^{6}$. El año siguiente, también Víctor Pagán, en su conspicuo trabajo sobre la presencia de Goldoni en España en el siglo XVIII ${ }^{7}$, da por sentada la autoría de Don Ramón. Por todas estas razones propendemos a aceptar la atribución como probable, si no como cierta, y ofrecemos lo que sigue de este estudio como material para establecer el usus scribendi del autor de Los Cazadores. Este criterio es el único que le queda disponible al estudioso de Don Ramón para añadir argumentos a la tesis de la autoría, ya que falta cualquier documentación externa al texto.

Como se ha dicho, la zarzuela de Los Cazadores es una traducción o, mejor dicho, una adaptación, del dramma giocoso de Carlo Goldoni Gli Uccellatori, estrenado en el teatro San Moisé de Venecia en el carnaval de 1759. La ópera de Goldoni la había representado en lengua italiana en la península Ibérica ya cuatro años atrás, en el teatro de la Santa Creu de Barcelona, la compañía de Francesc Creus, de la que formaban parte algunos célebres cantantes italianos que, en la mayoría de los casos, pisaban por primera vez las escenas españolas. No se sabe si encontró el gusto del público, ni cuántas veces fue representada. Pero sabemos que Creus volvió a ponerla en escena, con una compañía completamente renovada, en Barcelona en el mismo año, y más tarde, en 1767, en Palma de Mallorca, durante la única temporada operística de la que gozó la

4. Juan Sempere y Guarinos, Ensayo de una biblioteca de los mejores escritores del reinado de Carlos III, Madrid: Imprenta Real, 1785-1789.

5. A. Recasens Barberà, Las Zarzuelas de Antonio Rodríguez de Hita (1722-1787); contribución al estudio de la zarzuela madrileña hacia 1760-1770, tesis Doctoral, Université Catholique de Louvain, Septiembre 2001, p. 211 ss.

6. María Carmen Lafuente Niño, Ascensión Aguerri Martínez, eds., Ramón de la Cruz en la Biblioteca Histórica Municipal: material para su estudio, Madrid: Biblioteca Histórica Municipal, 1996.

7. Víctor Pagán, El teatro de Goldoni en España, tesis doctoral, Departamento de Filología Española, II, Facultad de Filología, Universidad Complutense de Madrid 1997. 
isla durante el siglo XviII ${ }^{8}$. De estas representaciones quedan los preciosos testimonios de los libretos que se distribuían durante la función y se vendían en casa del impresor, y que proporcionan importante información sobre la labor a la que se sometía el texto goldoniano para presentarlo al público español ${ }^{9}$. Se cantaba en italiano, pero el libreto llevaba una traducción de servicio junto al texto original, para que el público pudiese seguir con facilidad la acción y, sobre todo, el texto de las arias. En las dos ediciones de Barcelona y de Palma se nota, en primer lugar, que se ha añadido un personaje, que nada tiene que ver con la acción pensada por Goldoni, y que servía para proporcionarle un papel al cantante serio Antonio Pini, marido de la Graciosa protagonista. Casi todas las arias, sobre todo las serias, se sustituyen por otras, en la mayor parte sacadas de óperas de Metastasio, que probablemente les fueran más familiares a los cantantes; ya que solían preparar obras nuevas muy rápidamente; por lo que, de esta forma, economizaban esfuerzos. Hablaremos más adelante de la eventual relación entre estas traducciones de servicio y el trabajo de Ramón de la Cruz: por ahora nos limitamos a dar una descripción de las variaciones estructurales a las que el sainetero somete la obra del dramaturgo italiano.

La Zarzuela de los Cazadores está dividida en dos actos, mientras que el dramma giocoso tenía tres: esta labor de unificación y reducción la imponía el género, ya que la ópera buffa italiana solía estructurar la acción en tres partes, mientras que la zarzuela obligaba a más brevedad, y solo a dos partes. Ninguno de los testimonios que se conservan de la zarzuela proporciona una división en escenas, aunque estén completas las indicaciones de salida y entrada de personajes, y los cambios de escenografía. Es, sin duda, una versión muy distinta del original italiano: siguiendo las características del género, eminentemente popular, el sainetero elimina a los personajes serios del Marqués y la Condesa, reduciendo el reparto sólo a los bufos, cuyos enlaces amorosos están invertidos con respecto al original (Justo/Cecco está enamorado de Martina/ Mariannina en lugar que de Juliana/Roccolina). Las piezas de las escenas que incluían a los nobles y que el traductor no quiere perder (sobre todo las arias), están reintegradas en escenas protagonizadas por los demás personajes. Aunque Cruz mezcle material de los tres actos para formar sólo dos, el finale del acto I se sigue correspondiendo con el finale del acto I del original. Asimismo, el finale del acto II corresponde al finale del acto III del original. En general, las partes cantadas mantienen más deuda con el texto italiano, mientras que

8. Para más detalles sobre estas representaciones, y sobre las compañías que las llevaron al cabo, cfr. Josep Joaquim Esteve, I Drammi Giocosi in viaggio fra Barcellona, Palma di Maiorca, Madrid e Valenza. Un affare di impresari e cantanti, en "Problemi di Critica Goldoniana», XIV, 1 (2007), pp. 155-175.

9. Para informaciones más detalladas sobre los cambios a los que se sometió el libreto goldoniano, v. la base de datos del proyecto de investigación de la Universidad Autónoma de Barcelona «La Bottega di Goldoni»: http://goldoni.cerhum.es/goldoni/publiques/traduccionscasid.php?trid=56\&menu_idioma=cas. 
las mayores innovaciones se encuentran en las partes recitadas, más fáciles de alterar sin tener que intervenir en la música.

La Zarzuela de los Cazadores encontró el gusto del público, y fue un razonable éxito: se puso en escena por primera vez en las ya mencionadas fiestas en casa del Embajador de Nápoles, el 20 de Enero de 1764, pero en el mismo año obtuvo la licencia para representarse en los teatros públicos, y a partir del mes de Diciembre se puso en escena a menudo en Madrid, primero en el teatro del Príncipe y luego en el teatro de la Cruz ${ }^{10}$.

Como ya señalaba Recasens, quedan tres testimonios del texto de la zarzuela: dos manuscritos y uno impreso. Desgraciadamente, no se puede afirmar, con el estudioso, que «el texto traducido para las fiestas de Enero es el mismo que el de las representaciones públicas de Diciembre» ${ }^{11}$ : sin duda se trata de la misma zarzuela, pero, como se verá, los tres ejemplares transmiten tres textos significativamente distintos.

Los testimonios manuscritos se conservan en la Biblioteca Histórica Municipal de Madrid. Voy a llamar A el testimonio que lleva la localización: Tea 1-189-5 A y A bis el guión de música que lo acompaña. Este testimonio es muy interesante porque lleva escritas las marcas de los censores para los teatros públicos, y la fecha de cada intervención censoria. Se distinguen claramente dos manos, que suelen corresponder a dos niveles de revisión del texto, la censura clerical, y la censura civil; ahora bien, aquí parecen haberse dividido el trabajo por actos, concentrándose cada uno en una mitad de la zarzuela. Una tercera mano firma con el nombre de «Salaverri» la aprobación definitiva, el 10 de Noviembre de 1764:

Execútese con arreglo a las censuras

Salaverri

Con arreglo a las censuras

Puede representarse esta comedia en Madrid y Noviembre 241764

En el verso de la portada se encuentran algunas líneas de la mano censoria que será responsable de las censuras del segundo acto; lleva el nombre de Don Joseph Armendariz y Arbeloa, y la fecha de 3 de Noviembre:

10. Estas las fechas de las representaciones (cfr. René Andioc y Mireille Coulon, Cartelera teatral madrileña del siglo XVIII, 1708-1808, Toulouse: Presses Universitaires du Mirail, 1996):

Madrid, Teatro del Príncipe

1764: de 10 a 21 y de 27 a 31 de Diciembre

1675: de 28 a 30 de Junio

1767: de 16 a 20 de Febrero

1768: 22, 25, 27, 29, 31 Agosto

1771: 29-30 Junio; 4 Julio

Madrid, Teatro de la Cruz

1770: 12-13 Junio

11. A. Recasens, op. cit. p. 212. 
Madrid 3er Noviembre de 1764

Pase al fiscal de comedias, y con su censura tráigase.

La mano que censura el primer acto aparece por primera vez debajo de la de Armendariz, y se distingue de ella por ser algo temblorosa, y escribir con una tinta de un negro muy intenso. Firma con el nombre Antón Pablo; el apellido empieza por una F, pero queda ilegible por haberse desgarrado el folio. Escribe Antón Pablo, a 7 de Noviembre:

Señor, con la licencia de VS. puede representarse esta especie de comedia, dividida en dos actos: pues nada sustancial hallo, que impida ejecución, omitiendo unos versos que van tachados en el Acto primero: valido para Madrid y Noviembre 7 de 1764.

Antón Pablo F†

Vuelve Armendariz a aparecer, con su logo, al fondo de la última página de la zarzuela, proporcionando otra vez la fecha del 3 de Noviembre:

Madrid, 3 de Noviembre de 1764

Extiéndase la licencia para que se pueda representar.

Pero la aprobación más extensa de Armendariz se encuentra en la última hoja del pliegue, escrita cambiando la orientación de la hoja para tener el lado largo arriba, dos días más tarde que los comentarios en las primeras páginas, y dice:

Nos el Licenciado Don Joseph Armendariz y Arbeloa Pbro Heminente Vicario de esta villa de Madrid y su Partido

Damos lizenzia para que se pueda representar la comedia intitulada en las selvas sabe amor tender sus lazos mejor Atento a que de nuestra orden à sido vista y reconocida y no contenendo cosa alguna contra nuestra santa fe y buenas costumbres. Dada en Madrid, a cinco de Noviembre de mil setezientos sesenta y cuatro.

De estos datos podemos concluir que A se recopiló antes del 3 de Noviembre de 1764, que la primera mano que lo vio fue la de Armendariz, que interviene en el segundo acto, y que luego pasó a las manos de Antón Pablo, que encontró versos sospechosos en el primer acto y concluyó su trabajo censorio antes del 10 de Noviembre.

Parecen muy interesantes también las fechas que encontramos en el guión de música, A Bis, en cuya primera página se lee:

Música para la zarzuela de el Ex.mo S.or embajador de Nápoles. Los Cazadores, año 1764 . Enero 20 de 1764.

Resulta evidente que la fecha de recopilación del guión de música corresponde a la puesta en escena de la zarzuela, con ocasión de las fiestas por la boda de María Luisa y Leopoldo celebradas en casa del embajador de Nápoles en el 
mes de enero de 1764, y no a su puesta en escena en el teatro público, que tuvo lugar en diciembre y que necesitó pasar por la aprobación de la censura. Una prueba de la anterioridad de A bis con respecto a la censura de A se encuentra en el hecho de que el aria de Justo "Qué placer qué placer», que tacha Armendariz en A, está también tachada en A bis (n. 14,p. 13r). O sea, que quien recopiló las partes cantadas no sabía todavía que esa aria no se iba a poder ejecutar.

Llamaremos B el ejemplar de la BHM que tiene signatura Tea 1.189-5 B, y $\mathbf{B}$ bis su guión de música. Si A llevaba escrito el texto de las arias, y A bis lo repetía, aquí el caso es distinto: B lleva solo el texto recitado, y el verso inicial de las arias, mientras que las partes cantadas solo se encuentran en B bis, así que, para seguir el desarrollo de la acción, hace falta tener delante los dos testimonios contemporáneamente; se señala además el punto exacto en el texto recitado donde empezaba la música, antes de un aria. B no conoce intervención de censores; en la portada se lee:

Zarzuela de los Cazadores

En las selvas sabe Amor tender sus redes mejor ap. ${ }^{\text {to }} 1^{0}$

Legajo 4.

El tercer ejemplar que se conserva de la zarzuela se encuentra en la BNE y es el impreso que se hizo en ocasión de las fiestas en casa del embajador de Nápoles, en enero de 1764, tal como se lee en la portada:

FIESTAS que se han de hacer en casa del Excelentissimo Señor Príncipe de la Católica, Embajador de S:M: el Rey de las dos Sicilias, con motivo de los Desposorios de los Serenissimos Señores Archiduque Pedro Leopoldo y Doña María Luisa, Infanta de España. Apud: Joaquín Ibarra.

\section{Llamaremos este ejemplar Fiestas.}

También se conserva en la BHM un ejemplar manuscrito completo de la partitura (MUS 56-2), que comprende la parte cantada con bajo continuo y varias partichelas para las distintas clases de instrumentos.

Como se ha mencionado, los tres textos transmitidos de la zarzuela presentan entre sí muchas variantes, aunque quede muy claro que se trata de la misma zarzuela. Voy a proponer el análisis de algunos fragmentos de texto para llegar a definir la tipología de las variantes, y para poner los tres testimonios en relación entre sí, estableciendo cuál de ellos conserva el texto más parecido a lo que debió de salir de la pluma de Ramón de la Cruz, y cuál de ellos, entonces, se deberá utilizar para compararlo con el original italiano de Goldoni.

La primera serie de variantes que me parece útil analizar procede del primer acto. No podemos indicar la escena ya que el libreto no proporciona tal reparto del texto. Por esto, se indicarán las páginas, en el caso de Fiestas, y los folios, en el caso de los testimonios manuscritos A, Abis, B y Bbis. Formatos distintos 
de fuente indican variantes comunes a veces a A y B, a veces a A y Fiestas o B y Fiestas, o únicas de un testimonio ${ }^{12}$.

\begin{tabular}{|c|c|c|}
\hline $\mathrm{A}(4 \mathrm{r})$ & $B(2 v-3 r)$ & Fiestas $(10-11)$ \\
\hline Yo a Justo estoy adorando & Yo a Justo estoy adorando & Yo a Justo estoy adorando \\
\hline Con afecto singular & Con afecto singular & Por él me siento abrasar \\
\hline Y si él no me corresponde & Por él me siento morir ${ }^{13}$ & Si él no me quiere a mí, \\
\hline Porque a otra quiere más & Por él me siento quemar & O si a otra quiere más \\
\hline Bien pueden a Juliana & $Y$ si él no me quiere a mi, & Ya pueden a la Juliana \\
\hline Sus desdichas acabar. & O si a otra quiere más & Llevarla para enterrar. \\
\hline Pero yo soy una tonta, & Ya pueden a la Juliana & Pero yo soy una tonta \\
\hline que teniendo este pesar & Llevarla para enterrar. & Que teniendo este volcán \\
\hline no se lo doy a entender; & Pero yo soy una tonta & No se lo doy a entender \\
\hline y con esto doy lugar & Que teniendo este volcán & Y con esto doy lugar \\
\hline a que Martina le vaya & No se lo doy a entender & A que Martina le vaya \\
\hline ganando la voluntad. & Y con esto doy lugar & Ganando la voluntad. \\
\hline Pues no, que es gran bobería & A que Martina le vaya & Pues no, que es gran bobería \\
\hline Querer mi pena ocultar. & Ganando la voluntad. & Por culpa quedarse atrás \\
\hline Es verdad que es cosa dura & Pues no, que es gran bobería & Es verdad que es cosa dura \\
\hline Ir a rogar a un galán, & Por culpa quedarme atrús & Ir a rogar a un galán, \\
\hline Solamente de pensarlo & Querer mi pena ocultar & Solamente de pensarlo \\
\hline Mucha vergüenza me da & Es verdad que es cosa dura & Mucha vergüenza me da \\
\hline Jesús: eso es cosa fea & Ir a rogar a un galán, & Jesús eso es cosa fea \\
\hline Es una infame ruindad & Solamente de pensarlo & Es porquería y ruindad \\
\hline Y en una pobre pastora & Mucha vergüenza me da & $Y$ en una moza soltera \\
\hline Parecería muy mal & Jesús eso es cosa fea & Parecería muy mal \\
\hline Lo que en una señora & Es porquería, y ruindad & Lo que puedo únicamente \\
\hline Llegaran a murmurar; & $Y$ en una moza soltera & Es con arte y sin afán \\
\hline Porque el honor en los pobres, & Parecería muy mal & Darle a entender que me gusta: \\
\hline Dize también calidad. & Lo que en una casada & Procurarle agasajar; \\
\hline Y son los hombres hoy día & Llegaran a murmurar ${ }^{14}$ & Ponerme siempre a su lado \\
\hline La misma deslealtad. & Lo que puedo únicamente & Con cuidado hablarle más \\
\hline Lo que puedo únicamente & Es con arte y sin afán & De cuando en cuando, al descuido \\
\hline Es con arte y sin afán & Darle a entender que le quiero & Una guiñadita dar \\
\hline Darle a entender que le quiero & Procurarle agasajar; & $Y$ así como quien no quiere \\
\hline Procurarle agasajar; & Ponerme siempre a su lado & la cosa, irme con disfraz \\
\hline Ponerme siempre a su vista; & Con cuidado hablarle más & y muy poquitico a poco \\
\hline
\end{tabular}

12. Clave para leer las tablas de variantes:

Texto: variantes de A y B

Texto: variantes de B y Fiestas

Texto: Variantes de A sólo

Texto: Variantes de Fiestas sólo

Texto: Variantes de B sólo

Texto: Variantes de A y Fiestas

13. Añadido a posteriori, tinta distinta.

14. Añadido a posteriori, en el margen de la página, con otra tinta. 


\begin{tabular}{|c|c|c|}
\hline $\mathrm{A}(4 \mathrm{r})$ & $B(2 v-3 r)$ & Fiestas $(10-11)$ \\
\hline Y su inclinación notar; & De cuando en cuando al descuido & procurándome insinuar. \\
\hline De cuando en cuando al descuido & Una guiñadita dar & Si no ejecuto algo de esto \\
\hline Una guiñidita dar: & $Y$ aun como quien no quiere & Me muero, porque estoy tal \\
\hline Y en viendo que me aborrece, & la cosa, irme con disfraz & Que no puedo sujetarme \\
\hline Procurar escarmentar & y muy poquitico a poco & Y también si callo más \\
\hline$\underline{\text { Y la postrema del pecho }}$ & procurándome insinuar. & Mi pasión, temo que ún dia \\
\hline no se vuelva a congelar & Si no executo algo de esto & Reviente como costal. \\
\hline porque dolencia de celos & Me muero, porque estoy tal & \\
\hline $\begin{array}{l}\text { Más qué importa todo aquesto } \\
\text { Mán }\end{array}$ & $\begin{array}{l}\text { Que no puedo sujetarme } \\
\text { Y también si callo más }\end{array}$ & Arıa «No callar no quiero ya» \\
\hline Si es imposible callar & Mi pasión, temo que algún día & \\
\hline Y cuando del amor la fiebre & Reviente como costal. & \\
\hline Se asoma a los labios ya. & & \\
\hline Aria "No callar no quiero ya" & Aria "No callar no quiero ya» & \\
\hline
\end{tabular}

De esta primera serie se pueden empezar a sacar algunas observaciones. Lo primero que salta a la vista es la tendencia de A a refinar la expresión, con respecto a Fiestas y a B. El léxico y la retórica de A mueven hacia un lenguaje más melodramático, en el sentido italianizante del término, mientras que los demás testimonios transmiten expresiones populares, coloquiales, o simplemente muy coloridas: así, si en B y Fiestas «ya pueden a la Juliana llevarla para enterrar», en A Juliana sigue muriéndose, pero de forma más elegante, ya que «bien pueden a Juliana sus desdichas acabar». Lo que lleva a Juliana a la tumba es, en A, un "pesar», mientras que en B y Fiestas la pobre doncella tiene en el pecho nada menos que un "volcán». Lo que en A es una «infame ruindad», se vuelve en $\mathrm{B}$ y en Fiestas en una "porquería», y la pasión que en $\mathrm{A}$ «se asoma a los labios ya", en B y en Fiestas hacen temer a la joven enamorada que "reviente como costal». Asimismo, A evita todas las expresiones hechas, a costa de cambiar el sentido de las frases: así desaparece "como quien no quiere la cosa», $\mathrm{y}$ «muy poquitico a poco», dejando espacio a una verdadera reescritura del fragmento.

Además de esta tendencia estilística, a partir de esta tabla ya se puede empezar a afirmar que $B$, al recopilarse, disponía sea de las variantes proporcionadas por $\mathrm{A}$, sea de las variantes proporcionadas por Fiestas, y podía escoger entre ellas, y combinarlas según su mejor parecer. Así que, en el orden cronológico, es B el testimonio más tardío.

Aunque en general se pueda descubrir una tendencia de B a aceptar las variantes de Fiestas más que las de $\mathrm{A}$, hay lugares donde prefiere seguir $\mathrm{A}$, porque es más claro, en cuyo caso se trata de lectio facilior, o por otros criterios que no podemos reconstruir: 


\begin{tabular}{lll}
\hline A (10rss) & B (6rss.) & Fiestas (21) \\
\hline \multicolumn{1}{c}{ Perico } & \multicolumn{1}{c}{ Perico } & \multicolumn{1}{c}{ PERICO } \\
Antón, tú eres muy dichoso & Antón, tú eres muy dichoso & Antón, tú eres muy dichoso \\
Pues te andan al redopelo & Pues te andan al redopelo & Pues te andan al redopelo \\
Tantas mozas: ipero sabes & Tantas mozas: ipero sabes & Tantas mozas: ¿pero sabes \\
El recelo con que quedo? & El recelo con que quedo? & El recelo con que quedo?
\end{tabular}

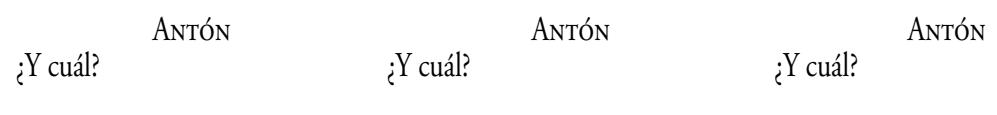

Perico

Que ninguna de esas

Que te hacen tantos obsequios,

Es gallina, por lo mismo,

Que has dicho, tengo este miedo. Que has dicho, tengo este miedo.

\section{Perico}

Que ninguna de esas

Que te hacen tantos obsequios,

Es gallina, por lo mismo,

ANTón

¿Por qué?

Perico

Porque las gallinas

son aves de poco vuelo,

y nunca caen en la red

porque no saben de enredos;

y esas que tú dices, hijo, procuran de ti otro cebo.

AnTón

¿Qué es lo que quieres decir?

[...]

\section{Perico}

Ay Antón, en esas cosas no creo, ni aun lo que veo: las mujeres saben mucho: cuando el galán es de pelo, y suda, a Diós, al instante todas se van derritiendo blandas son como manteca dulce como un caramelo. Las mujeres, que reciben, En grande ocasión las veo, Y si cuando ya han tomado Prosiguen después pidiendo, Mil veces peor, no es amor, Sino miserias del tiempo. ¡Con qué alhago, qué dulzura Con qué semblante risueño
AnTón

¿Por qué?

Perico

Porque las gallinas son aves de poco vuelo, y nunca caen en la red porque no saben de enredos; y esas que tú dices, hijo, procuran de ti otro cebo.

\section{AnTón}

¿Qué es lo que quieres decir? [...]

\section{Perico}

Ay Antón, en esas cosas no creo, ni aun lo que veo: las mujeres saben mucho: cuando el galán es de pelo, y suda, a Diós, al instante todas se van derritiendo blandas son como manteca dulces como un caramelo. Las mujeres, que reciben, En grande ocasión las veo, Y si cuando ya han tomado Prosiguen después pidiendo, Mil veces peor, no es amor, Sino miserias del tiempo. ¡Con qué alago, qué dulzura Música

\section{Perico}

Que ninguna de esas Que te hacen tantos obsequios, Es gallina, por lo mismo, Que has dicho, tengo este miedo.

¿Por qué? Antón

Perico

Porque las gallinas

Son las que ponen el huevo;

Yalo que dices, estas

No lo ponen: lejos de eso

Lo hacen por aprovecharse

De lo que hallan en tu cesto.

AnTón

¿Qué es lo que quieres decir?

[...]

\section{Perico}

Ay Antón, en esas cosas no creo, ni aun lo que veo: las mujeres saben mucho: cuando el galán es de pelo, y suda, a Diós, al instante todas se van derritiendo blandas son como manteca y tiernas como un cordero. Las mujeres, que reciben, Mala señal desde luego; Y si cuando ya han tomado Prosiguen después pidiendo, Mil veces peor: no es amor Sino interés, y comercio. ¡Con qué alhago, qué dulzura Con qué semblante risueño 


\begin{tabular}{|c|c|c|}
\hline A (10rss) & B (6rss.) & Fiestas (21) \\
\hline $\begin{array}{l}\text { Están siempre que las dan! } \\
\text { Si no, ¡qué cara de infierno! } \\
\text { ¡Qué palabritas tan dulces! } \\
\text { ¡Qué modos tan alhagüeños! } \\
\text { Y en fin, el pobre que cae } \\
\text { Levantarse tarde veo } \\
\text { Que a semejantes caídas } \\
\text { No hay estopas, hilas, ni huevo, } \\
\text { Con qué afecto entonces dicen: } \\
\text { Mi vida, mi alma, mi dueño. } \\
\text { Y entonces la etaran pegan }{ }^{15} \text { más } \\
\text { Cuando no tiene remedio. } \\
\text { Pero no habéis de engañarme, } \\
\text { chulitas, que ya os entiendo: } \\
\text { Y cuando mejor finjáis, } \\
\text { Más me he de estar yo riendo. } \\
\text { Aria: «A las mozas que reciben» }\end{array}$ & $\begin{array}{l}\text { Con qué semblante risueño } \\
\text { Están siempre que las dan! } \\
\text { Si no, iqué cara de infierno! } \\
\text { ¡Qué palabritas tan dulces! } \\
\text { QQué modos tan alagüeños! } \\
\text { Y en fin, el pobre que cae } \\
\text { Levantarse tarde veo } \\
\text { Que a semejantes caídas } \\
\text { No hay estopas, hilas, ni huevo, } \\
\text { Con qué afecto entonces dicen: } \\
\text { Mi vida, mi alma, mi dueño. } \\
\text { Y entonces la clavan más } \\
\text { Cuando no tiene remedio. } \\
\text { Pero no habéis de engañarme, } \\
\text { picaronas, que os entiendo: } \\
\text { Y cuando mejor finjáis, } \\
\text { Más me he de estar yo riendo. } \\
\text { Canta } \\
\text { Aria: «A las mozas que reciben» }\end{array}$ & 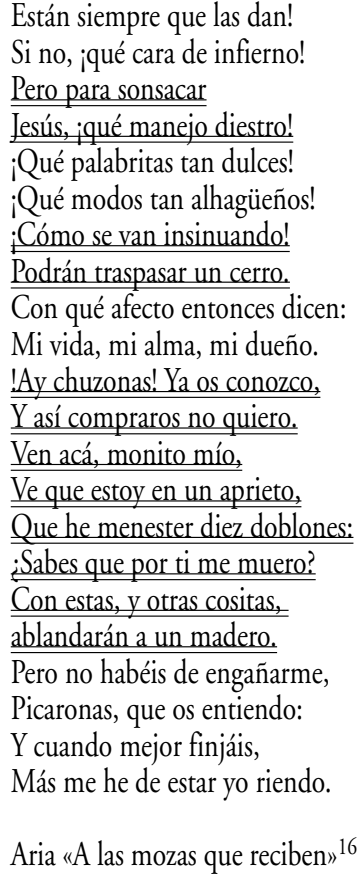 \\
\hline
\end{tabular}

En un solo lugar se encuentra una variante propia de B («que al sol te tiran los pelos»), y es el mismo fragmento donde más variantes tiene $B$ en común con Fiestas, rechazando sistemáticamente la lección de A. Aquí se encuentra más evidente el intento de $\mathrm{A}$ de hacer más clásico el lenguaje a veces muy popular de la zarzuela. A estas alturas ya se puede sospechar con fundamento que A quiera embellecer el texto porque tiene que presentarse ante la censura, y que por esto se puedan considerar las variantes de A si no apócrifas, sin duda posteriores a la redacción de Fiestas, que se debió imprimir en enero de 1764, mientras que A se redactó presumiblemente cerca de la fecha de las censuras que lleva encima, y con el fin precipuo de acabar en manos de censores. El lenguaje del texto transmitido por B y por Fiestas, de hecho, es más sencillo y popular que el lenguaje de $\mathrm{A}$, y hasta la elección de las imágenes deja más espacio a la inmediatez de la comparación que a la tradición retórica.

15. Esta variante se encuentra apuntada en el interlínea, para sustituir «clavan», compartido con B, pero tachado.

16. En el aria se encuentra la variante "picaronas», en lugar de «chulitas» transmitido por A. Tenemos que preferir la primera, ya que las arias son conservativas. 


\begin{tabular}{|c|c|c|}
\hline$A(14 r-16 r)$ & $B(9 r-10 r)$ & Fiestas (p. 30-32) \\
\hline $\begin{array}{l}\text { ANtón } \\
\text { A A Justo? Valedme cielos! } \\
\text { A aquese rapaz que ignora } \\
\text { La venda del dios flechero! } \\
\text { A un zagal tan presumido } \\
\text { Tan sin brío sin aliento } \\
\text { Que más parece juguete } \\
\text { De aquese vendado ciego. } \\
\text { Ay de mí que es imposible! } \\
\text { No, Juliana, no lo creo: } \\
\text { Cómo puede ella querer. } \\
\text { De solo pensarlo tiemblo, } \\
\text { A un rapaz sin experiencia. }\end{array}$ & $\begin{array}{l}\quad \text { ANTóN } \\
\text { ¿A Justo? Ese mocozuelo } \\
\text { Ese muchacho sin barbas } \\
\text { Que ahora es cuando va saliendo } \\
\text { Del cascarón; a ese soso } \\
\text { Tan sin brío y sin aliento } \\
\text { que más parece mujer? } \\
\text { No Juliana, no lo creo } \\
\text { Cómo puede ella querer } \\
\text { A tan tonto muchachuelo } \\
\text { No a un hombre como yo? }\end{array}$ & $\begin{array}{l}\quad \text { ANTóN } \\
\text { ¿A Justo? ¿Ese mocosuelo? } \\
\text { Ese muchacho sin barbas } \\
\text { Que ahora es cuando va saliendo } \\
\text { Del cascarón; a ese soso... } \\
\text { Tan sin brío y sin aliento } \\
\text { que más parece mujer? } \\
\text { No Juliana, no lo creo } \\
\text { Cómo puede ella querer } \\
\text { A tan tonto muchachuelo } \\
\text { No a un hombre como yo? }\end{array}$ \\
\hline $\begin{array}{l}\text { Juliana } \\
\text { Antón bien puedes creerlo } \\
\text { Pues que las mujeres suelen } \\
\text { Querer lo peor; y esto } \\
\text { No lo juzgues imposible } \\
\text { Pues cada día lo vemos. } \\
\text { Mira no hay en el lugar } \\
\text { Quien ya no repare en ello, } \\
\text { Porque aunque ellos hasta ahora } \\
\text { Se tratan con gran secreto } \\
\text { Y ponen gran disimulo; } \\
\text { Como amores y dineros } \\
\text { No se pueden encubrir; } \\
\text { Su amor está manifiesto } \\
\text { Ella lo bà a buscar siempre } \\
\text { Él la ve con ojos tiernos } \\
\text { Ella tiene gran cuidado } \\
\text { De hacerle un favor al vuelo } \\
\text { Y esto con grande recato } \\
\text { Él siempre la bà siguiendo } \\
\text { Con los ojos, y parece } \\
\text { Que su afición le trae ciego } \\
\text { Ella de otro no hace caso, } \\
\text { Él de ninguna hace aprecio, } \\
\text { Y en fin la verdad te digo, } \\
\text { Ya todo el lugar entero } \\
\text { está en que los dos se quieren. } \\
\text { Y por tanto te aconsejo } \\
\text { Que pues que te abrasas tanto } \\
\text { Cures el ardor con yelo. }\end{array}$ & $\begin{array}{l}\text { JuliaNA } \\
\text { Antón, tu pareces lelo } \\
\text { Pues te andas con imposibles } \\
\text { En cosas que estamos viendo. } \\
\text { Mira, no hay en el lugar } \\
\text { Quien ya no conozca esto } \\
\text { Porque aunque ellos hasta ahora } \\
\text { Se tratan con gran secreto } \\
\text { Y ponen gran disimulo; } \\
\text { Como amores y dineros } \\
\text { No se pueden encubrir, } \\
\text { Su amor está manifiesto } \\
\text { Ella lo bà a buscar siempre } \\
\text { Él la ve con ojos tiernos } \\
\text { Ella tiene gran cuidado } \\
\text { De traerle siempre el almuerzo } \\
\text { Y le da el mejor bocado } \\
\text { Él siempre la va siguiendo } \\
\text { Con los ojos, y parece } \\
\text { Que se la traga con ellos. } \\
\text { Ella de otro no hace caso } \\
\text { Él de ninguna hace aprecio } \\
\text { Y en fin hacen tales cosas } \\
\text { Que todo el lugar entero } \\
\text { está en que los dos se quieren. } \\
\text { Y así amigo te contesto } \\
\text { Que pues que te abrasas tanto } \\
\text { Procures echarte fresco. }\end{array}$ & $\begin{array}{l}\text { JuliaNA } \\
\text { Antón, tu pareces lelo } \\
\text { Pues te andas con imposibles } \\
\text { En cosas que estamos viendo. } \\
\text { Mira, no hay en el lugar } \\
\text { Quien ya no conozca esto } \\
\text { Porque aunque ellos hasta ahora } \\
\text { Se tratan con gran secreto } \\
\text { Y ponen gran disimulo; } \\
\text { Como amores y dineros } \\
\text { No se pueden encubrir, } \\
\text { Su amor está manifiesto } \\
\text { Ella lo va a buscar siempre } \\
\text { Él la ve con ojos tiernos } \\
\text { Ella tiene gran cuidado } \\
\text { De traerle siempre el almuerzo } \\
\text { Y le da el mejor bocado } \\
\text { Él siempre la va siguiendo } \\
\text { Con los ojos, y parece } \\
\text { Que se la traga con ellos. } \\
\text { Ella de otro no hace caso } \\
\text { Él de ninguna hace aprecio } \\
\text { Y en fin hacen tales cosas } \\
\text { Que todo el lugar entero } \\
\text { está en que los dos se quieren. } \\
\text { Así amigo te contesto } \\
\text { Que pues que te abrasas tanto } \\
\text { Te procures echar fresco. }\end{array}$ \\
\hline $\begin{array}{l}\qquad \text { ANTón } \\
\text { Juliana, si yo averiguo } \\
\text { Que lo que dizes es cierto, }\end{array}$ & $\begin{array}{l}\qquad \text { ANTón } \\
\text { Juliana, si yo averiguo } \\
\text { Que lo que dizes es cierto, }\end{array}$ & $\begin{array}{l}\qquad \text { ANTón } \\
\text { Juliana, si yo averiguo } \\
\text { Que lo que dices es cierto, }\end{array}$ \\
\hline
\end{tabular}




\begin{tabular}{lll}
\hline A (14r-16r) & B (9r-10r) & Fiestas (p. 30-32) \\
\hline He de tomar tal venganza & He de tomar tal venganza & He de tomar tal venganza \\
Y he de hazer... pero no quiero & Y he de hazer... pero no quiero & Y he de hacer... pero no quiero \\
$\begin{array}{l}\text { Dezir más, ya lo verán. } \\
\text { Ahora voy y les observo }\end{array}$ & Dezir más, ya lo verán. & Decir más, ya lo verán. \\
Quanto hagan: no he de perder & Ahora voy y les observo & Quanto hagan: no he de perder voy y les observo \\
Ni una palabra, un afecto & Quanto hagan: no he de perder \\
Y si beo que se quieren... & Ni una palabra, ni un gesto & Ni una palabra, ni un gesto \\
Si conozco que entre ellos & Si conozco que entre ellos & Y si veo que se quieren... \\
algo contra mi pasión & Alguna trama encubierta & Alguna trama encubierta \\
viven los sagrados cielos, & Por los huesos de mi abuelo & Por los huesos de mi abuelo \\
que me verán... ya tú sabes & que me verán: ya tu sabes & que me verán: ya tu sabes \\
que cuando en furor me enciendo & Que cuando en furor me enciendo Que cuando en furor me enciendo \\
no hay razón que me detenga & Soy un Diablo desatado & Soy un Diablo desatado \\
ni que me contenga freno, & Que todos me tienen miedo & Que todos me tienen miedo \\
que con amor no hay partido & Y voto á tal que al muchacho & Y voto à tal que al muchacho \\
ni para un zeloso hay riesgo. & Me lo sorbo como un huevo. & Me lo sorbo como un huevo. \\
& Vase &
\end{tabular}

Juliana

No ha sido muy malo pegarle

Este pesar tan recio

$\underline{\text { Ha ver si llega a enmendar }}$

su locura y devaneo

y desta forma logran

que Justo sea mi dueño.

Pero Antón es arrojado

Y a Justo en un lanze veo,

Mas el sabrá defenderse,

De su arrogancia y arresto,

Él hecha muchas bravatas,

Pero dice aquel proverbio

Que perro que ladra mucho

Muerde poco y yo no puedo

Sufrir a estos guapetones

Valientes y zahareños

Que matan a todo el mundo

Tan solo con el aspecto.

Yo aborrezco aquestos tales,

Me horrorizo de verlos,

Quánto son más agradables

Los tratables y alhagüeños

Que siempre hablan con dulzura

De corazoncito tierno

Que están como una jalea

Y nos dizen mil requiebros

Que los guapos matasietes

Son bravatas y son fieros

Y estos mazapanes dulces
JULIANA

No ha sido tan malo pegarle

Este parche tan de recio

Ha ver si sus tropelias

Meten allá algún enredo

Y puede ser mío Justo

que mucho mucho lo temo

Pero Antón es de los guapos

Que al sol te tiran los pelos

Luego en llegando el caso

Mucha flema y mayor miedo

Él hecha muchas bravatas,

Pero dice aquel proverbio

Que perro que ladra mucho

Muerde poco y yo no puedo

Sufrir a estos guapetones

Valientes y zahareños

Que matan a todo el mundo

Tan solo con el aspecto.

Quánto son más agradables

Los tratables y alhagüeños

Que siempre hablan con dulzura

De corazoncito tierno

Que están como una jalea

Y nos dizen mil requiebros

Que los guapos matasietes

Se vayan luego al infierno

[Son bravatas y son fieros

$\mathrm{Y}$ estos mazapanes dulces
Juliana

No ha sido tan malo pegarle

Este parche tan de recio

A ver si sus tropelias

Meten allá algún enredo

$Y$ puede ser mio Justo

que mucho, mucho lo temo

Pero Antón es de los guapos

Que al sol echará mil retos

Y luego en llegando el caso

Mucha flema y mayor miedo

Él echa muchas bravatas,

Pero dice aquel proverbio

Que perro que ladra mucho

Muerde poco y yo no puedo

Sufrir a estos guapetones

Valientes y zahareños

Que matan a todo el mundo

Y tienen duro el aspecto.

¿Quánto son más agradables

Los tratables y alhagüeños

Que siempre hablan con dulzura

De corazoncito tierno

Que están como una jalea

Y nos dizen mil requiebros?

Que los guapos matasietes

Se vayan luego al infierno

$\mathrm{Y}$ estos mazapanes dulces

Vengan para mi consuelo.

Canta 


\begin{tabular}{lll}
\hline A (14r-16r) & B (9r-10r) & Fiestas (p. 30-32) \\
\hline Vengan para mi consuelo. & Vengan para mi consuelo. & A estos fieros guapetones... \\
Canta & Canta & \\
A estos fieros guapetones... & A estos fieros guapetones... & \\
\hline
\end{tabular}

La imagen de Cupido se opone a la de un pollito que sale del cascarón; «sagrados cielos» se encuentran en lugar de demonios, el literario rapaz sustituye al más común mocosuelo, además alterado con diminutivo; desaparecen los huesos vengativos del abuelo, y la arrogancia de Antón pide que Justo se defienda (A: «Pero Antón es arrojado/ y a Justo en un lance veo,/ mas él sabrá defenderse,/ de su arrogancia y arresto»), en lugar de desahogarse enseguida en palabras vacías (Fiestas: «que al sol echará mil retos»). Encontramos aquí otro lugar del que resulta evidente que B disponía sea de A, sea de Fiestas, ya que recoge las dos variantes transmitidas y elige a posteriori entre ellas la variante de Fiestas:

Se vayan luego al infierno

[Son bravatas y son fieros

Los lugares más interesantes son, desde luego, los que llevan las tachaduras de la censura, sea en el primero, sea en el segundo acto. En el primer acto la mano temblorosa de Antón Pablo tacha algunos versos de la introducción a un aria que se ha transmitido casi sin variaciones desde el texto italiano, "Gallinetta che s'adira», o sea "La gallina que se enoja», y que explicaban de forma excesivamente clara el doble sentido del apacible aria:

\begin{tabular}{|c|c|c|}
\hline$A(8 r-9 v)$ & $\mathrm{B}(5 \mathrm{v}-6 \mathrm{r}) \mathrm{B}$ bis $7 \mathrm{r}$ & Fiestas (18-21) \\
\hline \begin{tabular}{l}
\multicolumn{1}{c}{ ANTón } \\
Ay Perico, si las vieras \\
Te diera gota coral, \\
No es por la caza, que ellas \\
así me lo han dicho ya \\
sino que andan mil zelillos \\
que ardiendo en ellas se están \\
con algunos araños \\
$\underline{\text { llega el cuento a rematar }}$ \\
y así cuando no les doy \\
al demonio arañarán
\end{tabular} & $\begin{array}{l}\quad \text { ANTóN } \\
\text { Ay Perico, si las vieras! } \\
\text { Se las lleva Satanás: } \\
\text { No es por la caza, que ellas } \\
\text { así me lo han dicho ya } \\
\text { sino que tienen mil celos } \\
\text { que ardiendo en ellas se están } \\
\text { y así cuando no les doy } \\
\text { al demonio arañarán }\end{array}$ & $\begin{array}{l}\quad \text { AnTón } \\
\text { Ay Perico, si las vieras! } \\
\text { Se las lleva Satanás: } \\
\text { No es por la caza, que ellas } \\
\text { así me lo han dicho ya } \\
\text { sino que tienen mil celos } \\
\text { y al demonio arañarán. }\end{array}$ \\
\hline $\begin{array}{l}\text { PERICo } \\
\text { Pues o no quiero su fiesta } \\
\text { Si en araño ha de parar. }\end{array}$ & $\begin{array}{l}\text { PERICo } \\
\text { Pues o no quiero su fiesta } \\
\text { Si en araño ha de parar. }\end{array}$ & $\begin{array}{l}\text { PERICo: } \\
\text { Pues o no quiero su fiesta } \\
\text { Si en araño ha de parar. }\end{array}$ \\
\hline $\begin{array}{l}\text { ANTón } \\
\text { O conmigo no hacen eso, } \\
\text { Ni se atreven à hablar }\end{array}$ & $\begin{array}{l}\text { ANTón } \\
\text { O conmigo no hacen eso, } \\
\text { Ni se atreven à hablar }\end{array}$ & $\begin{array}{l}\text { ANTón } \\
\text { O conmigo no hacen eso, } \\
\text { Ni se atreven à hablar }\end{array}$ \\
\hline
\end{tabular}




\begin{tabular}{ll}
\hline A (8r-9v) & B (5v-6r) B bis $7 \mathbf{r}$ \\
\hline $\begin{array}{l}\text { Si alguna se descompone, } \\
\text { y levanta la voz más, }\end{array}$ & $\begin{array}{l}\text { Si alguna se descompone, } \\
\text { y levanta la voz más, }\end{array}$ \\
$\begin{array}{l}\text { l punto le hecho un bufido, } \\
\text { y a Dios, no osa respirar. }\end{array}$ & $\begin{array}{l}\text { al punto le hecho un bufido, } \\
\text { y a Dios, no osa respirar. }\end{array}$
\end{tabular}

Perico

Según eso, eres, Antón,

El gallo de este corral?

\section{AnTón}

Perico, tú has dado en ello:

Has dado de par en par:

Un cathedrático insigne

No pudiera decir más.

Yo apuesto que no lo hubiera

Dicho ni aun el sagristán.

¡Un gallo con sus gallinas!

Muy definido está.

Di: ¿o has visto a la gallina,

Cuando anda por su corral,

En un montón poco a poco

El grano llega a picar.

El gallo viene corriendo

Por ver si parte se da

Đe aquella gustosa vaha

Que tantollega a gustar.

$Y$ mirando que to oeulta

fe pone a eacarear

ta gallina al momento

sepone toda a.tembtar

Y.con la cabeza baja

Eepide comopiedtadt:

Pues así, sin más ni menos

Así, sin menos ni más...

Pero espera, espera amigo

Que te lo quiero pintar.

(canta)

La gallina que se enoja

Con su gallo enamorado

Si repara que está airado

Le va siempre alrededor

Cacareando cococococo

Él la grita, y la gallina

A su gallo fiel se inclina

Como quien pide perdón

\section{Fiestas (18-21)}

Si alguna se descompone, y levanta la voz más, al punto le hecho un bufido, y a Dios, no osa respirar.

\section{Perico}

Según eso, eres, Antón,

El gallo de este corral?

\section{ANTón}

Perico, tú has dado en ello:

Has dado de par en par:

Un cathedrático insigne

No pudiera decir más.

Yo apuesto que no lo hubiera

Dicho el cura del lugar.

¡Un gallo con sus gallinas!

Muy bien difinido está.

Dì: ¿No has visto a la gallina,

Cuando anda por su corral

En un montón poco a poco

El grano llega a picar.

El gallo viene corriendo

Por ver si parte se da

Pues así, sin más ni menos

Así, sin menos ni más...

Pero espera, espera amigo

Que te lo quiero pintar.

(Canta)

La gallina que se enoja

Con su gallo enamorado

Si repara que está airado

Le va siempre alrededor

Cacareando cococococo

Él la grita, y la gallina

A su gallo fiel se inclina

Como quien pide perdón

\section{Perico}

Según eso, eres, Antón,

El gallo de este corral?

\section{AnTón}

Perico, tú has dado en ello:

Has dado de par en par:

Un cathedrático insigne

No pudiera decir más.

Yo apuesto, que no lo hubiera

Dicho el cura del lugar.

¡Un gallo con sus gallinas!

Muy bien dicho está.

Di: : No has visto a la gallina,

Que al gallo se va a buscar:

Que le llega poco a poco

Que alrededor se le va:

Que el gallo se pone erguido

Casi sin dignarse echar

Sus fieros ojos sobre ella

Yque si un grito le da

La gallina luego al punto

Se pone toda a temblar

Y.con la cabeza baja

Le pide como piedad?

Pues así, sin más ni menos

Así, sin menos ni más...

Pero espera, espera amigo

Que te lo quiero pintar.

(Canta)

La gallina que se enoja

Con su gallo enamorado

Si repara que está airado

Le va siempre alrededor

Cacareando cococococo

Él la grita, y la gallina

A su gallo fiel se inclina

Como quien pide perdón 
Este es uno de los lugares del texto que más variantes ofrece, por las distintas reacciones de los ejemplares a los vetos de la censura. $\mathrm{B}$ simplemente se salta los versos tachados, lo que confirma que fue recopilado, por lo menos, después de la intervención en la zarzuela de Antón Pablo en A; o sea después del 7 de Noviembre de 1764, que llega a constituir el terminus post quem para la recopilación de B. Muy interesante es la actitud de Fiestas hacia este fragmento de texto. Quien recopiló Fiestas antes del 20 de enero de 1764 no podía saber que esos versos los prohibiría la censura en noviembre, así que debió enterarse del riesgo celado detrás de esa aria, y procuró hacer más explícito el sentido en el que se debía tomar el discurso; o sea, él de la importancia de la jerarquía entre hombres y mujeres que se ha de mantener en el menaje familiar, y que, incluso, llega a demostrarlo la fenomenología natural. Fiestas ofrece otra variante interesante cuando dice «el Cura del lugar» donde A y B decían «el sagristán»: se puede sospechar que el sacristán sea variante elegante de A, sobrepuesta a la de Fiestas, debida al hecho de que el sacristán no tiene voto de castidad, mientras que el cura sí, y el contexto es sexualmente marcado.

El segundo acto parece más homogéneo que el primero: las variantes a menudo son desdeñables, y nunca se encuentran en partes cantadas. Las únicas intervenciones significativas en el texto se deben a la mano firme y a la tinta más clara de Armendariz. El censor suprime el aria de Justo Ay qué placer (p. 37rA), ahorrando así mucho esfuerzo al cantante, ya que el da-capo lleva 19 compases de vocalismos y trinos sobre la palabra $d a$. El aria se encuentra sin tachar en la partitura, lo que confirma la anterioridad de su recopilación con respecto a la censura en $\mathrm{A}$. De igual forma, ni A bis ni B bis llevan rastro de la intervención. A bis no necesitaba actualizarse con la censura, ya que esta se encontraba señalada en A que, como se ha dicho, lleva también escritas las partes cantadas. Asimismo, Armendariz señala con un $\mathrm{NO}$ el dueto Si Martina te prefiero (59r-60v A). El recopilador de B y B bis censura, siguiendo la indicación, el dueto y los versos que lo introducen, pero de forma muy distinta a como lo había hecho en el primer acto. Si entonces los versos tachados, introducción del aria La gallina que se enoja, estaban completamente ausentes en la redacción -que los saltaba de par en par-, aquí el recopilador actúa sobre el texto a posteriori, tachando los versos anteriores y siguientes al dueto en B (33r B), y sin molestarse siquiera en tacharlos todos en el guión (p23v-24r B bis). Fiestas, por supuesto, transmite sea el dueto sea los versos (126-128 Fiestas).

Tras este análisis de las convergencias y variantes entre los tres testimonios que sobreviven de la zarzuela de Los Cazadores, podemos observar que la mayoría de las variantes separan A de B y Fiestas; sin embargo, B tiene algunas variantes en común con $\mathrm{A}, \mathrm{y}$ a veces transcribe sea la lección $\mathrm{A}$, sea la lección de Fiestas. Luego elige la que le parece más apropiada y tacha la otra. Podemos entonces concluir que B cronológicamente sigue Fiestas y A.

Si nos encontrásemos ante una tradición cerrada, habría llegado la hora de hacer hipótesis sobre la genealogía de estos testimonios, y de proponer un stemma codicum. Desgraciadamente, la cuestión de la tradición de las zarzuelas 
- y de toda obra de arte performativa que se base en un texto literario- no es tan sencilla como la tradición de un texto sin más influencias que la acción de los copistas e impresores. Como delatan los datos que hemos ido acumulando en estas páginas sobre las distintas intervenciones que se sobreponen al texto de partida, desde cuando abandona la mesa del poeta hasta cuando se estrena en la escena y sale impreso para la lectura, intentar reducir a la lógica pura del error toda variante encontrada sería una tarea imposible, además de históricamente inexacta.

Por esto parece pertinente evocar el concepto, elaborado en los años ochenta por Cesare Segre, de diasistema. En su ensayo Crítica textual, teoría de los conjuntos y diasistema ${ }^{17}$, Segre observa que no todas las lecciones innovadas de un testimonio se pueden considerar errores en oposición con una lección conservada, que se supone más parecida al arquetipo, basándose en leyes como la lectio difficilior o el usus scribendi. Pero a menudo, en lugar de encontrarnos ante una pareja oposicional error vs lección correcta nos encontramos ante parejas de lecciones adiáforas o equipolentes, entre las que no se consigue elegir sin basarse «en una valoración del testimonio más que de cada variante» ${ }^{18}$. En nuestro caso, el embellecimiento del texto operado por el testimonio A nos ofrece un entero sistema de variantes que responden al mismo criterio estilístico, y constituyen, por lo tanto, un estrato homogéneo sobrepuesto al texto arquetípico. En el ejemplar B, sin embargo, encontramos una interferencia de sistemas: el sistema italianizante pro-censura de A, y el sistema transmitido por Fiestas, cronológicamente anterior a los dos testimonios manuscritos, y que probablemente lleve la menor cantidad de superestratos; visto que es anterior a la censura y que estaba dirigido a miembros de la nobleza para una función privada, situación en la que se toleraba más libertad que en las funciones para el teatro público. El sistema estilístico, además del sistema performativo, o sea las condiciones de ejecución del texto teatral, influyen entonces en la redacción del texto en cada fase de su transmisión, con o sin la intervención del autor. Concluye Segre:

En el caso más simple, el diasistema será el resultado del compromiso entre el sistema del texto $\left(S^{1}\right)$ y el sistema del copista $\left(S^{2}\right)$ : $D=S^{1}+S^{2}$. Pero a su vez la copia será transcrita por otro copista, con su sistema $S^{3}$, por lo que se tendrá: $\mathrm{D}=(\mathrm{S} 1+\mathrm{S} 2)+\mathrm{S}^{3}$, y así sucesivamente. Entonces la individuación de un stemma codicum coincidirá con una estratigrafía de los distintos diasistemas que coexisten en un texto ${ }^{19}$.

Traduciendo las indicaciones metodológicas de Segre en una representación gráfica de la situación de nuestros testimonios tendríamos un esquema parecido al siguiente:

17. En Cesare Segre, Semiótica filológica, texto y modelos culturales, trad. J. Muñoz Rivas, Murcia: Universidad de Murcia, 1990, pp. 53-62.

18. SEGRE, op. cit., p. 54.

19. SEGRE, op. cit., p. 58. 


\begin{tabular}{|l|l|}
\hline $\mathrm{S}^{3}=\mathrm{B}$ y B bis & $\begin{array}{l}\text { Engloba las correcciones de la censura, escoge entre variantes de } \\
\text { A y de Fiestas. }\end{array}$ \\
\hline $\mathrm{S}^{2}=$ A y Abis & $\begin{array}{l}\text { Está embellecido para presentarse a la censura y está adaptado a una } \\
\text { compañía de cantantes distinta de la inicial. }\end{array}$ \\
\hline $\mathrm{S}^{1}=$ Fiestas & $\begin{array}{l}\text { No tiene en cuenta la censura, lo representan los actores para los que } \\
\text { se ha escrito, así que no se cambian arias ni se suprimen compases. }\end{array}$ \\
\hline
\end{tabular}

De ahora en adelante, el texto que hemos de tomar por más cercano a las intenciones del autor de la zarzuela de Los Cazadores debe ser Fiestas, ya que ocupa el estrato más bajo del diasistema.

Ahora que hemos establecido que Fiestas es el texto más fiable entre los tres transmitidos, podemos proceder a la siguiente tarea: la de reconstruir la labor de traducción de Ramón de la Cruz, o de quien fuera el autor de la obra, y la de ver qué relación tiene el texto de llegada con el texto goldoniano de partida. Asimismo, indagaremos en el papel de mediación que puede haber ejercido la traducción barcelonesa de 1760 .

Nada más empezar el análisis de la traducción de Cruz frente a la traducción barcelonesa, salta a la vista la imposibilidad de una dependencia directa entre los dos textos. El texto barcelonés ni siquiera sirvió a Cruz de base para su obra, aunque hubiese decidido ignorar la traducción de servicio, porque donde Barcelona sustituye arias de Goldoni con arias ajenas, la mayor parte de Metastasio, Cruz sigue el texto de Goldoni.

Es el caso del aria de Roccolina Qual cocaletta (acto II, escena VII), traducida con el aria Qual zorzalilla de Juliana; mientras que Barcelona la sustituía con Quell'augellin domestico, que se encontraba en dos ediciones vienesas de Il Filosofo di Campagna:

\begin{tabular}{|c|c|c|c|}
\hline Princeps $^{20}$ & $\begin{array}{l}\text { Barcelona texto } \\
\text { italiano }\end{array}$ & $\begin{array}{l}\text { Barcelona traducción } \\
\text { castellana }\end{array}$ & Cruz (Fiestas p. 85) \\
\hline $\begin{array}{l}\text { Qual cocaletta } \\
\text { che a pelo d'acqua } \\
\text { va svolazzando } \\
\text { pietà cercando } \\
\text { dal suo cocal, } \\
\text { così ricerco } \\
\text { dal mio tesoro } \\
\text { qualche ristoro } \\
\text { per il mio mal. }\end{array}$ & $\begin{array}{l}\text { Quell'augellin domestico } \\
\text { Che tortorino ha nome } \\
\text { Ah! Se vedeste come } \\
\text { Ama la tortorella, } \\
\text { sempre d'intorno a quella } \\
\text { si vede svolazzar. } \\
\text { Anch'io così desidero } \\
\text { Tortora abbandonata, } \\
\text { d'essere accompagnata } \\
\text { da un tortorin che sappia } \\
\text { cosa vuol dir amar. }\end{array}$ & $\begin{array}{l}\text { Aquella ave domestica } \\
\text { Que tortolín se llama, } \\
\text { Ah! Si viesses cómo ama } \\
\text { La tortolilla bella } \\
\text { Siempre alrededor della } \\
\text { Se ve volatear. } \\
\text { Assí también es mi ánimo, } \\
\text { Tórtola abandonada, } \\
\text { De verme acompañada } \\
\text { De un tortolín, que sepa } \\
\text { Qué cosa sea amar. }\end{array}$ & $\begin{array}{l}\text { Qual zorzalilla } \\
\text { Que enamorada } \\
\text { Va voleteando } \\
\text { Piedad buscando } \\
\text { En su zorzal; } \\
\text { Así constante, } \\
\text { Busco en mi amante } \\
\text { Algún consuelo } \\
\text { Para mi mal. }\end{array}$ \\
\hline
\end{tabular}

20. Con Princeps entiendo la primera edición del libreto de Goldoni, para la representación en el teatro de San Moisé de Venecia en el carnaval de 1759 (SARTORI n. 24178). 
En los lugares donde Barcelona suprime arias en dialecto veneciano, Cruz se enfrenta con el texto dialectal, rellenando la laguna.

Es el caso de Barcelona, Acto II, escena XV (que corresponde a la escena XIV del original, habiéndose interpolado una escena XII para el nuevo personaje interpretado por Antonio Pini) se suprime un aria de Roccolina en dialecto veneciano Sti burletti, sti bravazzi y los cuatro versos que la introducían están variados. Suponemos que la variación del texto sea obra del adaptador de la compañía barcelonesa, Jácome Rust, porque los versos son más correctos en español que en italiano, en donde falta por lo menos una preposición («ite prigione», falta «in»). Cruz, por el contrario, traduce el texto de Goldoni y conserva el aria, con los cambios debidos a la adaptación para la acción de la zarzuela.

\begin{tabular}{|c|c|c|c|}
\hline Princeps & $\begin{array}{l}\text { Barcelona texto } \\
\text { italiano }\end{array}$ & $\begin{array}{l}\text { Barcelona traducción } \\
\text { castellana }\end{array}$ & Cruz (Fiestas p. 32) \\
\hline $\begin{array}{l}\text { Ella ha già deputato } \\
\text { Giudice della causa un } \\
\text { laureato. } \\
\text { Quelli che fanno i bravi } \\
\text { Non li posso soffrir: son di } \\
\text { buon core, } \\
\text { e posso dire anch'io una } \\
\text { canzoncina } \\
\text { d'una bella e gentil } \\
\text { venezianina. } \\
\text { Sti burletti, sti bravazzi } \\
\text { Sti cospetti, sti manazzi } \\
\text { Non li posso sopportar. } \\
\text { A mi me piase } \\
\text { Quei fantolini } \\
\text { Quei coresini } \\
\text { De marzapan. } \\
\text { Siei benedetti } \\
\text { Dove che i xe. } \\
\text { Via, signor secaggine, } \\
\text { vu no ghe intré. }\end{array}$ & $\begin{array}{r}\text {...Ella ha già deputato } \\
\text { Giudice della causa un } \\
\text { laureato. } \\
\text { Signori intanto ite } \\
\text { prigione } \\
\text { E si vedrà di voi chi } \\
\text { avrà ragione. }\end{array}$ & $\begin{array}{l}\text { Ella ya ha señalado } \\
\text { por juez de vuestra } \\
\text { causa un buen letrado, } \\
\text { Id, joh bravos!, por ahora a } \\
\text { a prisión. } \\
\text { Y se verá quien tiene más } \\
\text { razón. }\end{array}$ & $\begin{array}{l}\text { Que los guapos matasietes } \\
\text { Se van luego al infierno } \\
\text { Y estos mazapanes dulces } \\
\text { Vengan para mi consuelo. } \\
\text { Canta } \\
\text { A estos fieros guapetones } \\
\text { Tan bravíos, y matones } \\
\text { No los puedo tolerar: } \\
\text { A mí me gustan } \\
\text { Los dulcecitos, } \\
\text { Corazoncitos } \\
\text { De mazapán: } \\
\text { Sean benditos, } \\
\text { Pues que con ellos } \\
\text { Se tiene paz: } \\
\text { Sean benditos } \\
\text { Con ellos siempre } \\
\text { Quisiera estar. } \\
\text { Los matasietes } \\
\text { Al muladar, } \\
\text { Que el matadero } \\
\text { Es su lugar. }\end{array}$ \\
\hline
\end{tabular}

Barcelona interpola una escena en el acto II (escena XVII) para salvar para el público español una similitud entre las mujeres y los gatos que en el texto italiano está en dialecto veneciano y la canta Toniolo; aquí se inserta un diálogo singular entre Toniolo y Roccolina, donde la mujer le cuenta al cazador cómo un gato arañó a su hermana hace muchos años. Cruz traduce al castellano el texto veneciano, y no la escena interpolada de Barcelona. El sainetero malinterpreta los versos 6-7: el texto italiano quería decir que a las mujeres se les antoja decir que sí cada vez que el marido dice que no, mientras que Cruz escribe que se les ha que decir que sí aunque no razonen. 


\begin{tabular}{|c|c|c|c|}
\hline $\begin{array}{l}\text { Princeps (aria de } \\
\text { Toniolo, escena XV) } \\
\end{array}$ & $\begin{array}{l}\text { Barcelona texto italiano } \\
\text { (Roccolina) }\end{array}$ & $\begin{array}{l}\text { Barcelona traducción } \\
\text { castellana }\end{array}$ & $\begin{array}{l}\text { Cruz (Fiestas: aria } \\
\text { de Perico, p. 112) }\end{array}$ \\
\hline $\begin{array}{l}\text { Son le donne come i gatt, } \\
\text { le von esser carezzà. } \\
\text { Se ghe de qualche strapazz } \\
\text { Tiran fora quei unghiazz, } \\
\text { le comenza a graffignar. } \\
\text { Le von sempre dir de sí } \\
\text { Se de no dis el marí. } \\
\text { Za le donn è natt al mond } \\
\text { Per far l'omo desperar. }\end{array}$ & \begin{tabular}{l} 
Una piccola bambinella \\
Ero ancor di tenera età \\
E la povera mia sorella \\
Era ancor più piccina di me: \\
venne un gatto nero nero \\
con la coda... mi vien freddo \\
mia sorella... tremò tutta. \\
O che bestia brutta brutta! \\
Ci voleva graffignar. \\
Yo gridai: frusta via22; \\
fece gnau, e se n'andò, \\
ma saltò su, e giù, \\
parea matto, e ruppe un \\
poi torò, ci graffignò \\
poitto \\
e a la povera sorella \\
fece un segno, che mai se \\
\multicolumn{1}{c}{ n’andò. }
\end{tabular} & $\begin{array}{l}\text { Era yo muchacha chiquita, } \\
\text { niña de muy tierna edad, } \\
\text { y la pobre de mi hermanita } \\
\text { era aún más pequeñita que } \\
\text { yo. } \\
\text { Vino un gato negro negro } \\
\text { Con la cola... frío siento. } \\
\text { Mi hermana... toda pálpito. } \\
\text { Oh que animal tan maldito! } \\
\text { Queríanos arañar. } \\
\text { Yo grité: gato de ahí } \\
\text { Hizo mao, y se escapò; } \\
\text { Más saltò acá, y acullá: } \\
\text { Loco el gato rompió un } \\
\text { Ylato } \\
\text { Y volvió, y nos arañó } \\
\text { E hizo à la pobre de mi } \\
\text { hermana } \\
\text { Una señal que jamás se } \\
\text { borró. }\end{array}$ & $\begin{array}{l}\text { Son las mozas como gatos } \\
\text { A quien se ha de acariciar, } \\
\text { Y sus gustos contentar: } \\
\text { Si alguien les llega a enfadar, } \\
\text { Saben la pata sacar, } \\
\text { Y se ponen a arañar. } \\
\text { Aunque estén en frenesí } \\
\text { Se les ha de decir sí: } \\
\text { Ay! Las mozas sólo sirven } \\
\text { Para hacernos aburrir. }\end{array}$ \\
\hline
\end{tabular}

Cruz no se basa en la traducción barcelonesa ni siquiera cuando ella conserva un aria goldoniana, como en el caso del aria de Mariannina Senza padre, $e$ senza madre (Acto I, escena V), traducida con el aria Sin tener padre, ni madre, de Martina.

\begin{tabular}{|c|c|c|c|}
\hline Princeps & Barcelona texto italiano & $\begin{array}{l}\text { Barcelona traducción } \\
\text { castellana }\end{array}$ & Cruz (Fiestas p. 9-10) \\
\hline $\begin{array}{l}\text { Senza padre e senza madre } \\
\text { poverina che ho da far? } \\
\text { Una povera figliuola, } \\
\text { che ha paura di star sola, } \\
\text { si vorebbe accompagnar. } \\
\text { Un sposino galantino } \\
\text { mi potrebbe consolar }\end{array}$ & $\begin{array}{l}\text { Senza padre, e senza madre } \\
\text { poverina, che ho da far? } \\
\text { Una povera figliola, } \\
\text { che ha paura di star sola } \\
\text { si vorrebbe accompagnar. } \\
\text { Un sposino galantino } \\
\text { Io mi voglio procurar. }\end{array}$ & $\begin{array}{l}\text { Sin tener padre, ni madre } \\
\text { Infeliz, cómo he de estar? } \\
\text { Una pobre doncellita, } \\
\text { Que teme el estar solita } \\
\text { Se quisiera acompañar. } \\
\text { Un marido bien pulido } \\
\text { Por esso quiero buscar. }\end{array}$ & $\begin{array}{l}\text { Sin tener padre, ni madre, } \\
\text { Miserable, qué he de hacer? } \\
\text { Una triste huerfanita, } \\
\text { Que está sola, y pobrecita, } \\
\text { Quien le asista ha menester. } \\
\text { Un marido } \\
\text { Muy pulido } \\
\text { Mi fortuna puede hacer. }\end{array}$ \\
\hline
\end{tabular}

21. Ortolani (C. Goldoni, Tutte le Opere, Milano, Mondadori, 1956-1964, vol. 4) precisa en una nota al pie que esta "è l'aria di Petronio in Monsieur Petiton, parte II, scena IV». Por lo que he conseguido averiguar, esta breve obra en dialecto veneciano nunca ha sido traducida al español, así que la tradución no puede ser que obra de Cruz.

22. En este caso el texto español parece más correcto y fluido que el texto italiano que, por ejemplo, propone un inusual «frusta via!», en lugar de "pussa vía». 
Lo mismo pasa con el aria de Cecco Gli augelletti che volan d'intorno (acto I escena IX), que se vuelve el aria de Justo Los paxaritos, que veo volando. La traducción barcelonesa es fiel y literal, pero Cruz no la necesita para proporcionar la propia:

\begin{tabular}{|c|c|c|c|}
\hline Princeps & $\begin{array}{l}\text { Barcelona texto } \\
\text { italiano }\end{array}$ & $\begin{array}{l}\text { Barcelona traducción } \\
\text { castellana }\end{array}$ & Cruz (Fiestas p.14-15) \\
\hline $\begin{array}{l}\text { Gli augelletti che volan } \\
\text { d'intorno } \\
\text { buona preda mi fanno } \\
\text { sperar. } \\
\text { Quei fringuelli dovriano } \\
\text { cantar, } \\
\text { li vedo volar, } \\
\text { li sento cantar, } \\
\text { se s'invischian li voglio } \\
\text { pigliar. } \\
\text { Zitto zitto, non parlate, } \\
\text { non mi fate gl'augelli } \\
\text { scapar. } \\
\text { Eccone uno. } \\
\text { Eccone un altro. } \\
\text { Io son scaltro, so bene } \\
\text { uccellar. }\end{array}$ & 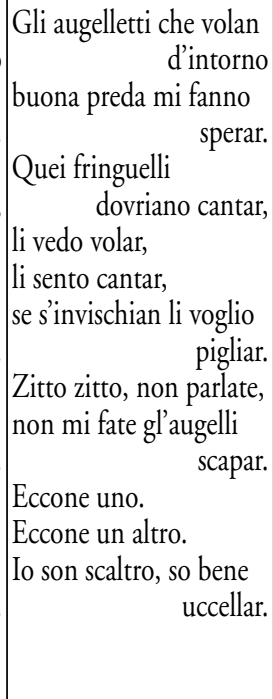 & 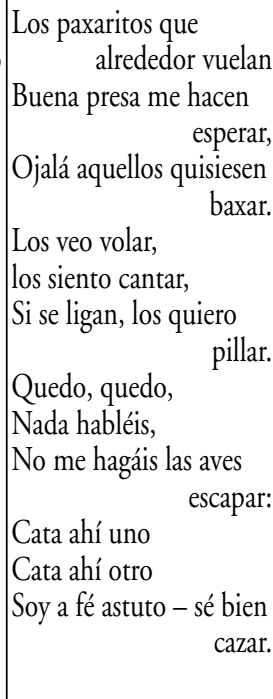 & 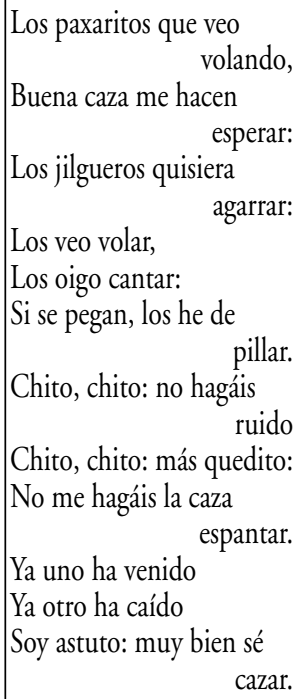 \\
\hline
\end{tabular}

Desde un punto de vista meramente cronológico, es posible que Cruz tuviese en sus manos el libreto barcelonés, pero ningún elemento del texto evidencia la existencia de un contacto entre la traducción del sainetero y la de Barcelona. En Cruz no se encuentran siquiera rasgos de los insertos apócrifos de Rust. Entonces, si Cruz tenía Barcelona en sus manos, él, con inteligencia, supo distinguir las partes originales de las apócrifas, y tuvo que hacer referencia a una edición del libreto en lengua italiana, para recuperar las arias que en la edición de Barcelona habían sido suprimidas o sustituidas con otras. Entonces, puedo afirmar con cierta seguridad que Cruz no conocía Barcelona y, si la conocía, prefirió otra edición italiana, probablemente la misma Princeps, que traducía sin mediaciones.

Existen sin embargo algunos lugares donde las semejanzas entre la traducción barcelonesa y la versión de Cruz llegan a ser literales. He aquí una lista completa $^{23}$ :

23. Los versos que se corresponden están subrayados. 


\section{Escena I acto I Vamos compañeros:}

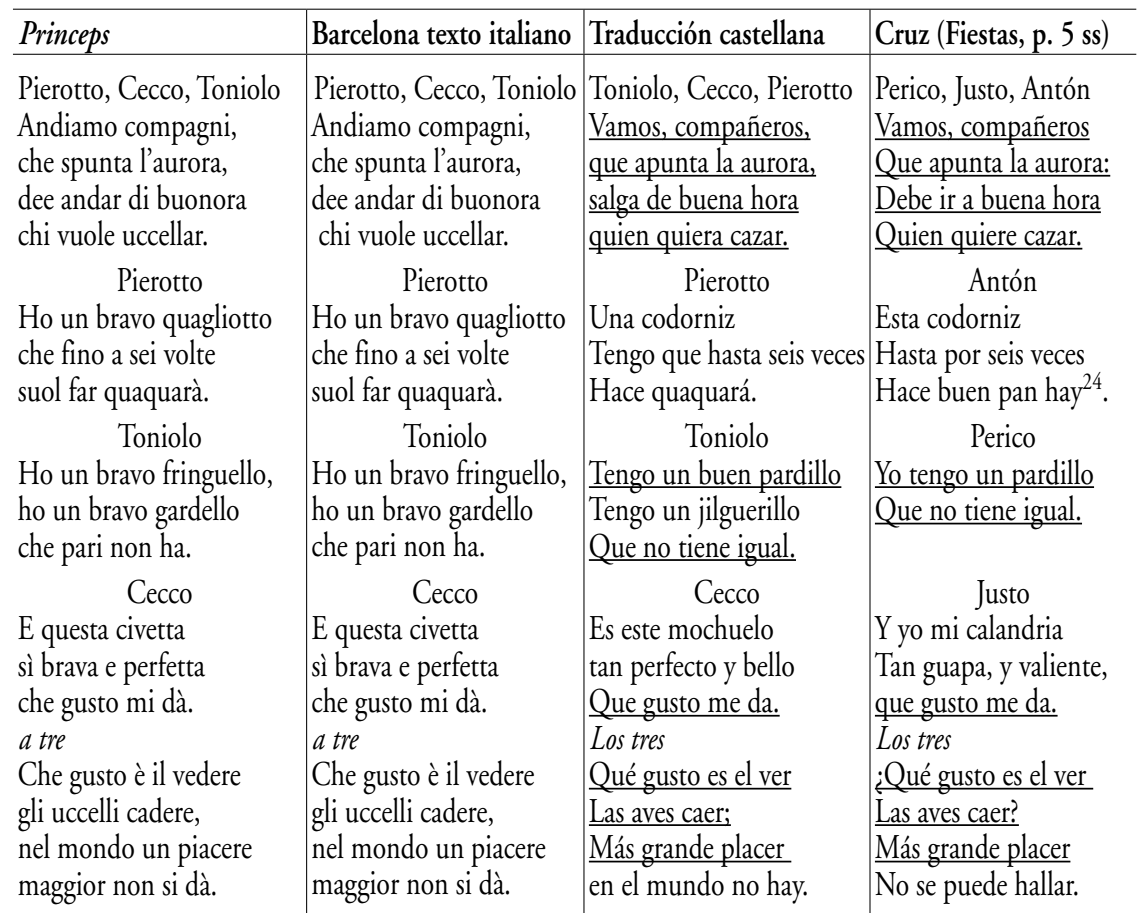

\section{Aria de Pierotto Nol so di certo (atto II scena IX)}

\begin{tabular}{|c|c|c|c|}
\hline Princeps & Barcelona texto italiano & Traducción castellana & Cruz (Fiestas, p. 55) \\
\hline $\begin{array}{c}\text { Nol so di certo ma mi fu } \\
\text { che Roccolina, che detto } \\
\text { Mariannina } \\
\text { abbian per esso del grande } \\
\text { affetto, } \\
\text { se questo è vero, lo vo' } \\
\text { ammazzar. } \\
\text { Con uno schioppo faccio il } \\
\text { colpetto, } \\
\text { con un coltello gli spacco il } \\
\text { petto } \\
\text { e poi le gambe gli vuo segar } \\
\text { e poi senzaltro lo lascio } \\
\text { andar. }\end{array}$ & $\mid \begin{array}{r}\text { Nol so di certo ma mi fu } \\
\text { detto } \\
\text { che Roccolina, che } \\
\text { Mariannina } \\
\text { abbian per esso del grande } \\
\text { affetto, } \\
\text { se questo è vero, lo vo' } \\
\text { ammazzar. } \\
\text { Con uno schioppo faccio il } \\
\text { colpetto, } \\
\text { con un coltello gli spacco } \\
\text { il petto } \\
\text { e poi le gambe gli vuo } \\
\text { segar } \\
\text { e poi senzaltro lo lascio } \\
\text { andar. }\end{array}$ & $\begin{array}{l}\frac{\text { No lo sé cierto, mas se }}{\text { me ha dicho }} \\
\text { Que Roccolina, que } \\
\text { Mariannina, } \\
\text { Aman a Cecco, } \frac{\text { con gran }}{\frac{\text { capricho }}{a}} \\
\text { Si es verdad esto le he de } \\
\text { matar } \\
\text { A escopetazos, a tierra le } \\
\text { echo } \\
\text { Con un cuchillo le passo } \\
\text { el pecho } \\
\text { Después las piernas le he } \\
\frac{\text { de cortar }}{\text { andar. }}\end{array}$ & 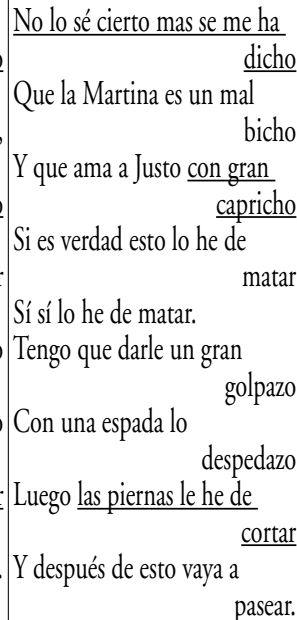 \\
\hline
\end{tabular}


No obstante, me parece que los casos citados se puedan reconducir a una práctica traductiva literal, que sigue el texto de partida palabra por palabra, sin que intervenga el filtro interpretativo o creativo del traductor. Cervantes había descrito bien esta costumbre traductiva en la famoso capítulo del Quijote donde el caballero andante visita una imprenta, no por casualidad en Barcelona:

Pero dígame vuestra merced, señor mío, y no digo esto porque quiero examinar el ingenio de vuestra merced, sino por curiosidad no más: ¿ha hallado en su escritura alguna vez nombrar piñata?

- Sí, muchas veces - respondió el autor. jote.

— ¿Y cómo la traduce vuestra merced en castellano? — preguntó don Qui-

- ¿Cómo la había de traducir — replicó el autor — sino diciendo 'olla'?

- iCuerpo de tal — dijo don Quijote—, y qué adelante está vuestra merced en el toscano idioma! Yo apostaré una buena apuesta que adonde diga en el toscano piace, dice vuestra merced en el castellano 'place', y adonde diga più dice 'más', y el su declara con 'arriba' y el giù con 'abajo'.

—Sí declaro, por cierto — dijo el autor—, porque esas son sus propias correspondencias.

-Osaré yo jurar - dijo don Quijote- que no es vuestra merced conocido en el mundo, enemigo siempre de premiar los floridos ingenios ni los loables trabajos. ¡Qué de habilidades hay perdidas por ahí! ¡Qué de ingenios arrinconados! ¡Qué de virtudes menospreciadas! Pero, con todo esto, me parece que el traducir de una lengua en otra, como no sea de las reinas de las lenguas, griega y latina, es como quien mira los tapices flamencos por el revés, que aunque se ven las figuras, son llenas de hilos que las escurecen y no se ven con la lisura y tez de la haz; y el traducir de lenguas fáciles ni arguye ingenio ni elocución, como no le arguye el que traslada ni el que copia un papel de otro papel ${ }^{24}$.

Toda correspondencia entre Los Cazadores de Cruz y Los Cazadores de Barcelona se puede entonces interpretar como una manifestación más de esta forma mecánica de traducir, que deja que las imágenes del original se entrevean a través de la obra del mediador lingüístico, como en un tapiz colgado al revés.

Quienquiera que sea, entonces, el autor de Los Cazadores, tenía acceso al libreto italiano, se enfrentaba con ello sin la mediación de la edición catalana. $\mathrm{Su}$ capacidad de transferir la trama, los personajes, y la misma métrica goldoniana en lengua castellana nos hace propender por un traductor-adaptador que tuviese una consolidada costumbre en la traducción de obras extranjeras, e italianas en particular, cuya identidad puede bien ser la del célebre sainetero Don Ramón de la Cruz.

24. M. de Cervantes, El ingenioso caballero Don Quijote de la Mancha, parte II, cap. LXII (ed. del Instituto Cervantes, dirigida por Francisco Rico, (C) Instituto Cervantes, 1997-2012, http://cvc.cervantes.es/literatura/clasicos/quijote/default.htm). 


\section{Bibliografía citada}

Andioc, René y Coulon, Mireille, Cartelera teatral madrileña del siglo xviii, 17081808, Toulouse: Presses Universitaires du Mirail, 1996.

Cotarelo y Mori, Emilio, Don Ramón de la Cruz y sus obras, Madrid: RAE, 1899.

Esteve, Josep Joaquim, «I Drammi Giocosi in viaggio fra Barcellona, Palma di Maiorca, Madrid e Valenza. Un affare di impresari e cantanti», en Problemi di Critica Goldoniana, XIV, 1 (2007), pp. 155-175.

Goldoni, C., Tutte le Opere, a cura di G. Ortolani, Milano: Mondadori, 1956-1964, vol. 4.

GonzÁlez Cruz, David, «Las bodas de la realeza y sus celebraciones festivas en España y América durante el siglo XVIII", en Espacio, tiempo y forma, serie IV, Historia Moderna, t. 10, (1997), pp. 227-261.

Lafuente Niño, María Carmen y Aguerri Martínez, Ascensión (eds.), Ramón de la Cruz en la Biblioteca Histórica Municipal: material para su estudio, Madrid: Biblioteca Histórica Municipal, 1996.

Pagán, Víctor, El teatro de Goldoni en España, tesis doctoral, Departamento de Filología Española, II, Facultad de Filología, Universidad Complutense de Madrid, 1997.

Recasens Barberà, Albert, Las Zarzuelas de Antonio Rodríguez de Hita (1722-1787); contribución al estudio de la zarzuela madrileña hacia 1760-1770, tesis doctoral, Université Catholique de Louvain, septiembre 2001, p. 211 ss.

SARTORI, Claudio, I libretti italiani a stampa dalle origini al 1800, Cuneo: Bertola \& Locatelli, 1994.

SEgre, Cesare, Semiótica filológica, texto y modelos culturales, trad. J. Muñoz Rivas, Murcia: Universidad de Murcia, 1990.

SEmpere y Guarinos, Juan, Ensayo de una biblioteca de los mejores escritores del reinado de Carlos III, Madrid: Imprenta Real, 1785-1789.

\section{Fuentes electrónicas}

La Bottega di Goldoni, Base de datos, ${ }^{\odot}$ Centre d'Estudis i de Recerca d'Humanitats, Facultad de Filosofía y Letras, Universitat Autònoma de Barcelona 2013, dir. por Rossend Arqués Corominas (http://goldoni.cerhum.es).

Carlo Goldoni, Drammi per Musica, ${ }^{\circ}$ Anna Laura Bellina y Luigi Tessarolo et al., Università di Padova - Casa di Goldoni, 2010 (www.carlogoldoni.it).

M. de Cervantes, El ingenioso caballero Don Quijote de la Mancha, ed. del Instituto Cervantes, dirigida por Francisco Rico, ${ }^{\odot}$ Instituto Cervantes, 1997-2012 (http:// cvc.cervantes.es/literatura/clasicos/quijote/default.htm). 